\title{
Germination response of Russian wildrye to varia- tions in seed mass at fluctuating temperatures
}

\author{
W. ERIC LIMBACH AND C.A. CALL
}

Authors are with the Department of Biological Sciences, Idaho State University, Pocatello, Ida. 83209; and the Department of Range Science, Utah State University, Logan, Utah 84322. At the time of the research, Limbach was research assistant, Department of Range Science, Utah State University.

\begin{abstract}
The effects of seed mass and fluctuating temperatures on the germination and heterotrophic seedling development of 3 seed sources of Russian wildrye, Psathyrostachys juncea (Fisch.) Nevski, were studied. Seeds that weighed 2.4, 3.0, 3.6, and 4.2 $\pm 0.1 \mathrm{mg}$ of each seed source were germinated in an unlighted incubation chamber at $5-10^{\circ} \mathrm{C}, 5-15^{\circ} \mathrm{C}, 10-15^{\circ} \mathrm{C}$, and $10-20^{\circ} \mathrm{C}$. Germination and heterotrophic seedlings development were assessed using: 1) mean time to germinate $\left(T_{1}\right), 2$ ) the mean proportion of seeds to germinate (G) and 3) mean maximum radicle and coleoptile extension. Data were analyzed using a $4 \times 4 \times 3$ factorial analysis of variance $(n=144)$ comprised of main effects, temperature $(T)$, seed mass $(M)$, and seed source (S). Time to germination was significantly affected by $\mathrm{T}(\mathrm{F}=647.44, \mathrm{P}<0.0001), \mathrm{S}(\mathrm{F}=28.29, \mathrm{P}<0.0001)$ and the $\mathrm{T} \times \mathrm{S}$ $(F=4.71, P<0.0003)$ and $S \times M(F=2.21, P<0.0489)$ interactions. The mean maximum proportion of seeds to germinate was significantly affected by $T(F=13.63, P<0.0001), S(F=10.53, P<0.0001), M$ $(F=8.11, P<0.0001)$ and the $T \times M$ interaction $(F=2.21, P<0.0276)$. Radicle extension was significantly affected by $T(F=21.94$, $P<0.0001), S(F=14.29, P<0.0001), M(F=12.70, P<0.0001)$, and the $T \times S(F=13.69, P<0.0001)$ interaction. Coleoptile extension was significantly affected by $\mathrm{T}(\mathrm{F}=810.24, \mathrm{P}<0.0001)$, $\mathrm{S}$ $(\mathrm{F}=68.83, \mathrm{P}<0.0001), \mathrm{M}(\mathrm{F}=56.00, \mathrm{P}<0.0001)$, and the $\mathrm{T} \times \mathrm{M}$ ( $F=3.84, P<0.0003)$ interaction. Apparently, Syn-A seeds germinate more vigorously and have longer coleoptiles than Vinall but apparent differences remain confounded between seed sources since the effects of seed age and maternal environment cannot be eliminated from the study.
\end{abstract}

Key Words: coleoptile development, cumulative germination, Psathyrostachys juncea, radicle development, seed size

Russian wildrye, Psathyrostachys juncea (Fisch.) Nevski, is an Eurasian bunchgrass well adapted to grazing use on the Great Plains and the Intermountain West of North America. Russian wildrye begins growth early in the spring (Smoliak and Johnson 1980), is drought hardy (Currie and White 1982, Asay and Johnson 1980) and can persist under fairly high grazing intensi-

This research was funded by the Utah Agricultural Experiment Station (UAES). This manuscript has been approved as UAES Joumal Paper No. 4783. ties (Laude and Fox 1982, Asay et al. 1985). In the cold desert shrub steppe, however, it is more difficult to establish than crested wheatgrass, Agropyron cristatum (Gaetrn), another bunchgrass native to Eurasia (Drawe et al. 1975, Asay and Johnson 1980).

In studies with Russian wildrye seed mass (size) has been correlated with seedling vigor (McKell 1972) as expressed by seedling emergence (Asay and Johnson 1980, Berdahl and Barker 1984, Limbach and Call 1995a) and seedling establishment in the field (Kittock and Patterson 1962, Limbach and Call 1995b). Heavy seed mass has been correlated with seedling vigor of other grass species such as bluebunch wheatgrass (Pseudoroegneria spicata Löve, var inerme), intermediate wheatgrass (A. intermedium (Host) Beauv.), sand wheatgrass (A. psammophilum Gillett and Senn) blue grama (Bouteloua gracilis (H.B.K.) Lag. ex Steud.), and sheep fescue (Festuca ovina L.) (Kittock and Patterson 1962, Hunt and Miller 1965, Carren et al. 1987, Zhang and Maun 1990).

The seed source "Syn-A", a germplasm of Russian wildrye, Psathyrostachys juncea Fisch. (Nevski), establishes more success fully than Vinall Russian wildrye in field trials (personal communication, Kay Asay, USDA-ARS, Logan, Utah). The success of Syn- $A$ in the field may be due, in part, to greater mean seed mass and to other, undefined, genotypic characteristics. The seed source Syn-A was selected, in part, for seed "size" (mass).

\section{Materials and Methods}

Cumulative germination and heterotrophic development

The 3 seed sources of Russian wildrye were: 1. "Vinall" produced in North Dakota in 1985 (VN85), 2. "Vinall" produced in Montana in 1986 (VN86), and 3. Syn-A, produced in Utah in 1987 (SA87). The seed source Syn-A is an unregistered synthetic hybrid developed by grass breeders at the USDA-ARS, Logan, Utah. At the time of this investigation (June-September 1988), seeds had been stored for less than 3 year, 2 year, and 1 year, respectively.

One thousand randomly selected seeds (caryopses with lemmas and paleas) of each seed source were weighed to the nearest 0.1 $\mathrm{mg}$. The seed-mass distribution of each seed source was analyzed for mean seed mass, standard deviation, skewness, kurtosis, and departures from normality. Subsequently, 4 seed mass classes of $2.4,3.0,3.6$, and $4.2 \pm 0.1 \mathrm{mg}$ were chosen for further analysis of seed-mass effects. This range of seed masses accounted for $84 \%$ 
of VN85 seeds, $83 \%$ of VN86 seeds, and $84 \%$ of SA87 seeds. Seed moisture contents varied from 8-13\%.

Seeds were surface sterilized in a $0.5 \%$ sodium hypochlorite solution and rinsed in sterile distilled water. Sterilized seeds were placed in 9-cm petri dishes that were lined with Whatman No. 1 filter paper, wrapped in transparent plastic film to limit evaporation and moistened daily. Each dish contained 12 seeds of a single source and $0.1 \mathrm{mg}$ seed mass. Thus, 1296 seeds were monitored at each temperature regime.

Seeds were germinated in an unlighted biological incubator under alternating-constant temperature regimes of $5-10^{\circ} \mathrm{C}$, 5-15 $5^{\circ} \mathrm{C}, 10-15^{\circ} \mathrm{C}$, or $10-20 \pm 0.5^{\circ} \mathrm{C}$ (12 hours-12 hours). These 4 temperature regimes bracket temperatures that seeds are likely to experience during spring germination in the Intermountain Region. Mean time to germination was calculated for each petri dish. A seed was considered to have initiated germination when its radicle protruded beyond the lemma-palea envelope by at least $0.2 \mathrm{~mm}$. Radicle and coleoptile lengths were measured daily to the nearest $0.5 \mathrm{~mm}$ using an ocular micrometer until coleoptiles were pierced by the first leaf, at which time the maximum lengths were recorded and the seedling discarded. Radicle lengths always reached maximum before coleoptile lengths. Germination and seedling development were monitored under a green safelight (Hubert and Funke 1937). Length of these investigations varied from about 2 weeks at the warmer temperatures to about 4 weeks at the cooler temperatures.

\section{Statistical Analyses:}

The mean time to germination $\left(T_{1}\right)$, the mean maximum proportion of seeds to germinate (G), using arc-sine transformed values and mean maximum radicle and coleoptile lengths were analyzed using analysis of variance (SAS Institute 1985) with 4 seed mass classes, 4 temperature regimes, 3 seed sources and 3 replicates $(n=144)$. Multiple mean comparisons were made using Tukey's studentized range test (Zar 1984). Residuals were plotted and tested for normality using the Shapiro-Wilk statistic (Shapiro and Wilk 1965).

\section{Results}

Seed mass frequency distributions appeared fairly normal for all three seed sources. Seed source SA87 had a seed mass distribution, however, that was more positively skewed $\gamma_{1}=$ $0.457)$ and leptokurtotic $\left(\gamma_{2}=1.853\right)$ than either VN85 $\left(\gamma_{1}=\right.$ $\left.0.077, \mathrm{~g}_{2}=-0.335\right)$ or VN86 $\left(\gamma_{1}=0.032, \gamma_{2}=-0.135\right)$. Seed source SA87 had a significantly greater mean seed mass (3.6 $\mathrm{mg} \pm 0.03 \mathrm{mg})$ than VN85 $(2.9 \mathrm{mg} \pm 0.02 \mathrm{mg})$ or VN86 $(3.0$ $\mathrm{mg} \pm 0.03 \mathrm{mg})(\mathrm{P}<0.0001)$. Mean seed masses for the 2 Vinall seed sources were not significantly different.

Mean time to germination was significantly influenced by temperature $(\mathrm{T})(\mathrm{P}<0.0001)$ and seed source $(\mathrm{S})(\mathrm{P}<0.0001)$ as well as the $\mathrm{T} \times \mathrm{S}(\mathrm{P}<0.0003)$ and $\mathrm{S} \times \mathrm{M}(\mathrm{P}<0.05)$ interactions. The effect of seed mass $(M)$, however, was not significant $(P=0.3)$. Mean time to germination across seed sources and mass classes was inversely related to temperature (Fig. 1a) and seed mass (Fig. 1b). Seed source SA87 had a significantly shorter $T_{1}$ than VN85 and VN86 (Fig. 1c). Sources VN85 and VN86 were not significantly different for mean to germination.

Mean germination $(G)$ was significantly effected by temperature $(P<0.0001)$, seed source $(P<0.0004)$, and seed mass $(P<$ $0.0002)$ though none of the higher order interactions were significant. Mean germination in the $5-10^{\circ} \mathrm{C}$ regime was significantly different than mean germination at warmer temperatures (Fig. 2a). Mean germination increased with seed mass (Fig. $2 b$ ) with only $2.4 \mathrm{mg}$ and $4.2 \mathrm{mg}$ seed classes showing significant mean separations. Seed source SA87 had significantly greater mean germination than VN85 or VN86 (Fig. 2c); values of $G$ of VN85 and VN86 were not significantly different. The significant $T \times M$ interaction for mean germination showed that there were different temperature optima for light $(2.4-3.0 \mathrm{mg})$ and heavy $(3.6-4.2$ mg) seeds (Fig. 3a).

Mean maximum radicle lengths were significantly affected by temperature $(\mathrm{P}<0.0001)$, seed source $(\mathrm{P}<0.0001)$, seed mass $(\mathrm{P}<0.0001)$ and the $\mathrm{T} \times \mathrm{S}$ interaction $(\mathrm{P}<0.0001)$. Radicle lengths at $10-15^{\circ} \mathrm{C}$ were significantly greater than at the other temperature regimes (Fig. 4a) tended to increase with increases in seed mass class (Fig. $4 \mathrm{~b}$ ), and

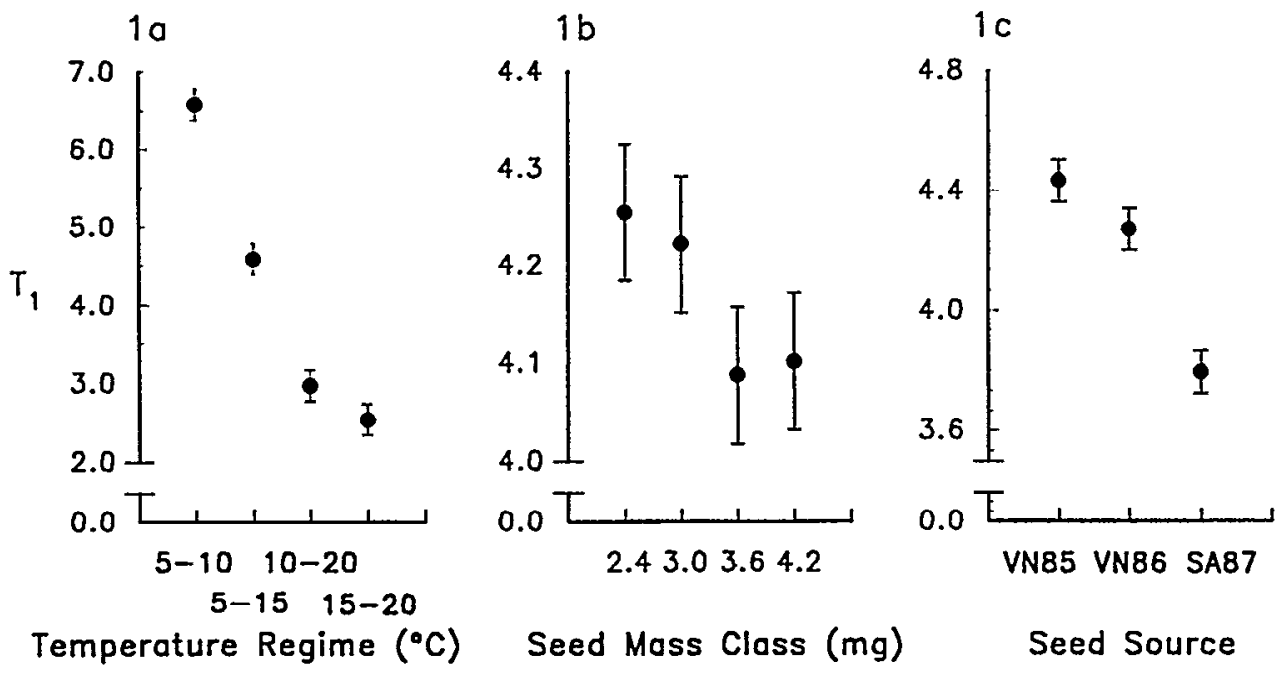

Fig. 1. The response of mean time to germination $\left(T_{1}\right)$ of dark-germinated seeds of Russian wildrye to variations in temperature regime (1a), seed mass class (1b) and seed source (1c). Vertical bars represent \pm 1 standard error. 


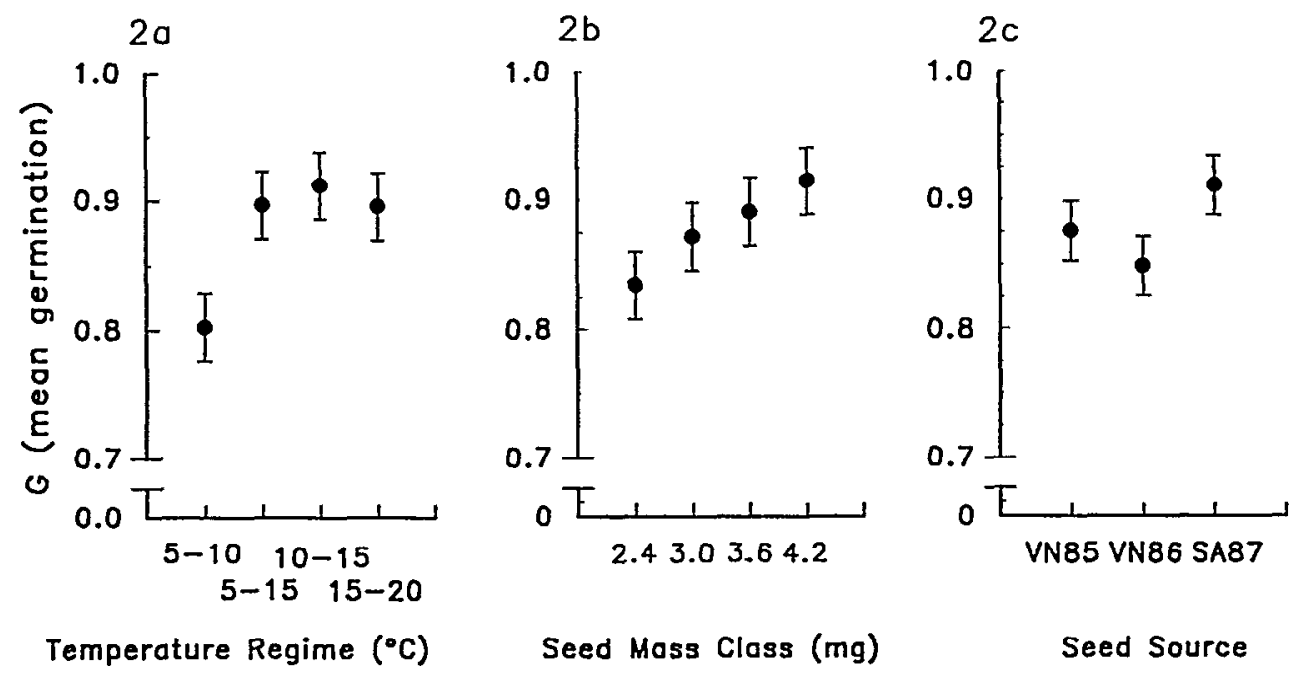

Fig. 2. The response of the mean germination (G) of Russian wildrye seeds to variations in temperature regime (2a), seed mass class (2b) and seed source (2c). Vertical bars represent \pm 1 standard error.

were significantly greater for SA87 and VN85 than for VN86 (Fig. 4c).

Mean maximum coleoptile lengths were significantly affected by temperature $(P<0.0001)$, seed mass $(P<0.0001)$, seed source $(P<0.0001)$ and the $T \times M$ interaction $(P<0.0003)$. Coleoptile lengths increased at warmer temperature regimes (Fig. 4a) and seed mass classes (Fig. 4b). Seed source SA87 had a significantly longer mean coleoptile length than either VN85 or VN86 (Fig. 4c). Sources VN85 and VN86 were not significantly different for coleoptile length. Coleoptiles of heavy seeds $(4.2 \mathrm{mg})$ grew longer than coleoptiles of lighter seeds $(2.4,3.0,3.6 \mathrm{mg})$ in the warmer temperature regimes (Fig. $3 \mathrm{~b}$ ).

A small percentage ( 3.0 to $7.2 \%$ ) of seeds failed to germinate. A Chi-square test of independence for seed failure between seed mass class and temperature regime was not significant $(P=0.3126)$, thus, seed failure was independent of the effects of seed mass or temperature regime. Subsequently, failed seeds were determined as dormant or non-viable using the tetrazolium test (Pili-Sevilla 1987). Dormant seed percentages ranged from 0.2 to $1.9 \%$ across seed mass classes and temperature regimes. A Chi-square test of independence for seed dormancy between seed mass and temperature regime was not significant $(P=0.7360)$, thus, seed dormancy was also independent of the effects of seed mass and temperature regime.

\section{Discussion}

In this study, the effects of seed mass (size) on germination and heterotrophic seedling development of Russian wildrye confirm

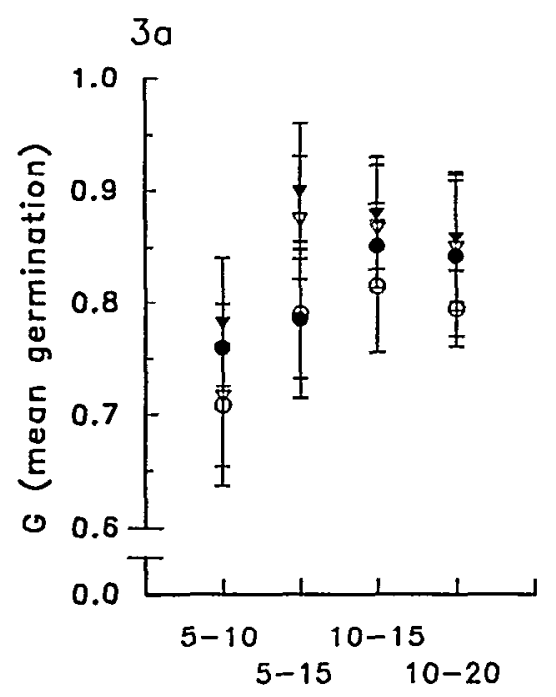

Temperature Regime $\left({ }^{\circ} \mathrm{C}\right)$

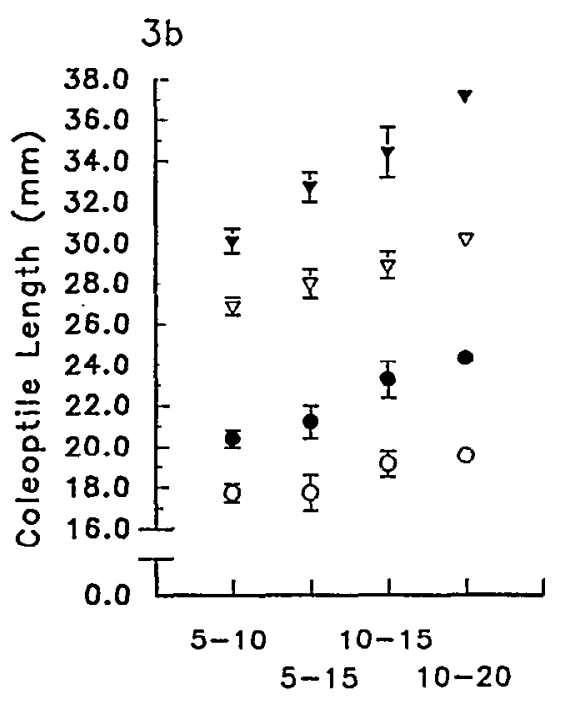

Temperature Regime $\left({ }^{\circ} \mathrm{C}\right)$

Fig. 3. The responses of the mean germination (3a) and mean maximum coleoptile length (3b) of dark-germinated Russian wildrye seeds to the interaction of temperature regime and seed mass class $(O=2.4 \mathrm{mg}, 0=3.0 \mathrm{mg}, \nabla=3.6 \mathrm{mg}, \nabla=4.2 \mathrm{mg})$. Vertical bars represent \pm 1 standard error. 


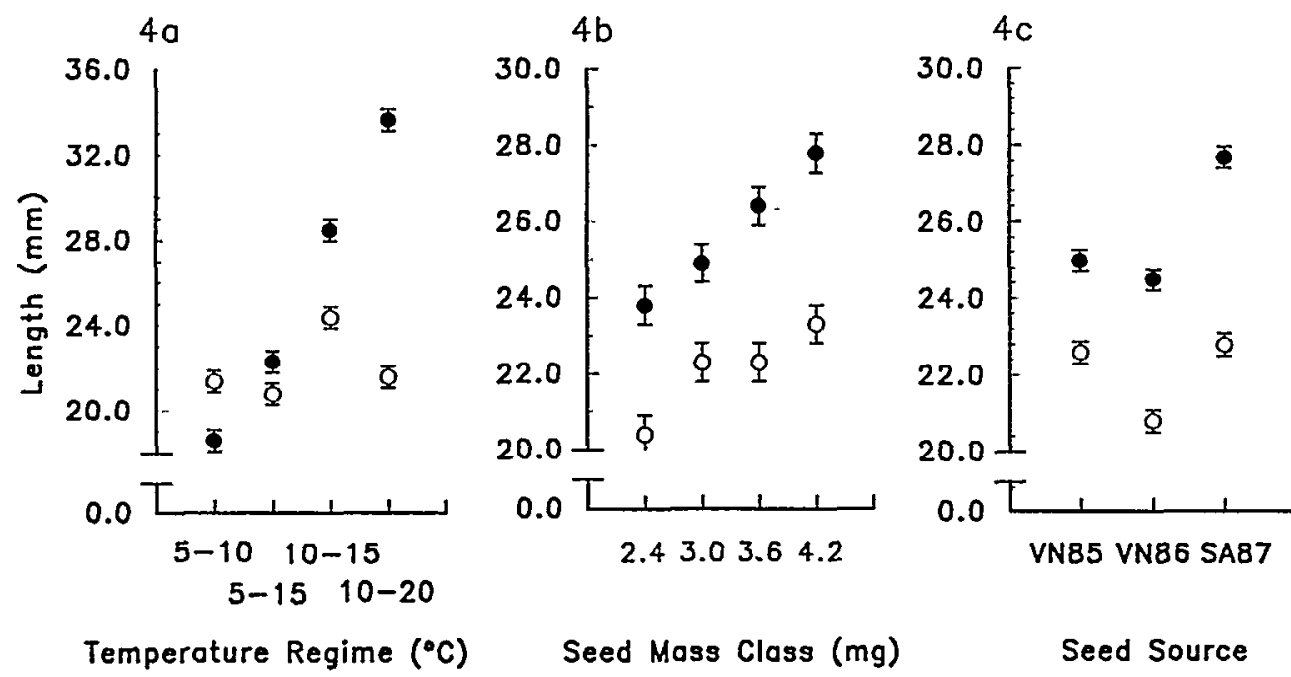

Fig. 4. The responses of radicle and coleoptile growth (mean maximum lengths) of dark-germinated seeds of Russian wildrye to variations in temperature regime (4a), seed mass class $(4 b)$ and seed source $(4 c)(O=$ radicle, $O=$ coleoptile). Note different scales on y-axes. Vertical bars represent \pm 1 standard error.

the results of other authors on the response of seed germination and seedling emergence to seed size (Kittock and Patterson 1962, Hunt and Miller 1965, Asay and Johnson 1980, Berdahl and Barker 1984, Carren et al. 1987, Zhang and Maun 1990, Limbach and Call 1995a). Heavy seeds had greater proportion of seeds to germinate, and longer radicles and coleoptiles than light seeds. Longer seminal roots and coleoptiles should favor early seedling development in these seedlings. Radicle lengths did not increase with seed masses beyond $3.0 \mathrm{mg}$ while coleoptile lengths increased significantly over the entire seed mass range from 2.4 to $4.2 \mathrm{mg}$.

Germination and heterotrophic seedling development predictably increased with temperature. Germination rate (expressed as a decrease in $T_{1}$ ) and coleoptile lengths increased in the warmer temperature regimes. Maximum germination percentage and maximum radicle extension, however, were at $10-15^{\circ} \mathrm{C}$ and not in the $10-20^{\circ} \mathrm{C}$ regime.

The seed source Syn-A displayed more vigorous germination and seedling developmental characteristics than Vinall though the observed differences may be due to other factors not tested here, such as maternal environment or effects of seed age. Mean time to germination for Syn-A was shorter than for Vinall and this effect was most pronounced at the coolest $\left(5-10^{\circ} \mathrm{C}\right)$ temperature regime. The seed source Syn-A also had a greater germination percentage and longer coleoptiles than Vinall seedlings. Thus, this seed lot of Syn-A could be expected to emerge earlier, in greater numbers, and from deeper planting depths than the Vinall seed sources.

The confounding effects of seed age and maternal environment cannot be separated from the effects of seed source on germination and heterotrophic seedling development in this study. The negative slope in mean time to germination (Fig. 1c) could be due to younger seeds germinating more rapidly than older seeds but the trend could also be due to differences in maternal environments. The trends among seed sources for mean germination (Fig. 2c) and root and shoot extension (Fig. 4c), however, might be better related to maternal environment than to seed age.

\section{Literature Cited}

Asay, K.H. and D.A. Johnson. 1980. Screening for improved stand establishment in Russian wild ryegrass. Can. J. Plant Sci. 60:1171-1177.

Asay, K.H., W.H. Horton, and W.T. Hansen. 1985. New grasses for intermountain rangelands. Utah Sci. 46:119-123.

Berdahl, J.D. and R.E. Barker. 1984. Selection for improved seedling vigor in Russian wild ryegrass. Can. J. Plant Sci. 64:131-138.

Carren, C.J., A.M. Wilson, R.L. Cuany, and G.L. Thor. 1987. Caryopsis weight and planting depth of blue grama. 1. Motphology, emergence, and seedling growth. J. Range Manage. 40:207-211.

Currie, P.O. and R.S. White. 1982. Drought survival of selected forage grasses commonly seeded in the northern Great Plains. Can. J. Plant Sci. 62:949-955.

Drawe, D.L., J.B. Gumbles, and J.F. Hooper. 1975. Establishment of Russian wildrye on foothill ranges in Utah. J. Range Manage. 28:152-154.

Hubert, B. and G.L. Funke. 1937. The phototropism of terrestrial roots. Biol. Jaarboek, Univ. Stichting van Belgie, Antwerp. p 286-306 + fig.

Hunt, O.J. and D.G. Miller. 1965. Coleoptile length, seed size, and embryos in Intermediate Wheatgrass, Agropyron intermedium (Host) Beav. Agron. J. 57:192-195.

Kittock, D.L. and J.K. Patterson. 1962. Seed size effects on performance of dryland grasses. Agron. J. 54: 277-278.

Laude, H.M. and R.E. Fox. 1982. Tillering differences after close clipping in Russian Wildrye and Tall Fescue. Crop Sci. 22:978-980.

Limbach, W.E. and C.A. Call. 1995a. Emergence and development of Russian wild ryegrass seedlings as influenced by seed source, seed mass, and seeding depth in an artificial medium. Can. J. Plant Sci. 75:167-170.

Limbach, W.E. and C.A. Call. 1995b. Establishment of Psathyro stachys juncea (Fisch.) Nevski seedlings on a foothill range of central Utah, USA. J. Arid Environ. 30:000-000.

McKell, C.M. 1972. Seedling vigor and seedling establishment, p. 74-89. In: V.B. Youngner and C.M. McKell (ed.), The biology and utilization of grasses. Academic Press, N.Y.

Pili-Sevilla, E. 1987. Germination and tetrazolium testing. Seed Sci. Tech. 15:691-698.

SAS Institute. 1985. SAS user's guide: Statistics. 5th Edition. SAS Institute Inc., Cary, N.C.

Shapiro, S.S. and M.B. Wilk. 1965. An analysis of variance test for normality (complete samples). Biometrika 52:591-611.

Smoliak, S. and A. Johnson. 1980. Russian wildrye lengthens to grazing season. Rangelands 2:249-250.

Zar, Jerrold H. 1984. Biostatistical Analysis, 2nd Edition Prentice Hall, Englewood Cliffs, N.J.

Zhang, J. and M.A. Maun. 1990. Seed size variation and its effects on seedling growth in Agropyron psammophiltum. Bot.Gaz. 151:106-113. 